\title{
The Relations between Parental Friendships and Children's Friendships: Self-Report and Observational Analysis
}

\author{
Sandra D. Simpkins and Ross D. Parke
}

\begin{abstract}
The relations between the quality of mothers' and fathers' friendships and that of their children's friendships was examined. One hundred twenty-five fourth-grade children (9 year olds) completed the Friendship Quality Questionnaire. Observational measures of the target children playing with their self-selected friend were also collected. Mothers and fathers separately completed the Friendship Quality Questionnaire about their best friend. Results indicated that children's self-reports and observational measures of friendship quality were not highly correlated for girls, but were moderately associated for boys. The quality of mothers' and fathers' friendships was related to the quality of children's friendships, but the nature of the relations with children's friendships differed for girls and boys. The implications of these findings for the socialization of friendship patterns and the assessment of children's friendships were noted.
\end{abstract}

\section{INTRODUCTION}

Most research on the familial correlates of children's peer relationships has focused on peer group acceptance (Ladd \& LeSieur, 1995; Parke \& Ladd, 1992). Because the processes and outcomes characterizing friendships are distinct from other measures of peer competence, such as social acceptance, it is likely that the familial antecedents will differ as well (Bagwell, Newcomb, \& Bukowski, 1998). The focus of the current study was to explore the links between the quality of parents' friendships and the quality of their children's friendships, as measured through both observational and self-report measures. This study was exploratory because research on the links between parents' and children's friendship qualities has only recently begun. Furthermore, the correspondence between children's behavior with a friend and perceptions of that friendship is also a relatively unresearched area. In addition to a review of relevant empirical research, theory accounting for the links between parents' and children's friendships is also reviewed. Although the mechanisms of these theories were not tested in this study, it is important to set this study within a larger theoretical framework for future research.

The Links between Mothers' and Fathers' Friendships and Children's Friendships

Parental friendships may influence children's friendships in a variety of ways. First, through observation of their parents' interactions with their friends, children may learn how to interact with friends, solve conflicts, and utilize friends to deal with problems. Second, adults who have close, supportive friendships have more adequate parenting skills, especially under stressful conditions (Cochran \& Brassard, 1979; Hartup \& Stevens, 1997). Friends provide parents with emotional and tangible support, help in childrearing, and serve as parenting role models (Cochran \& Brassard, 1979). The impact of these two processes is likely to vary with quality of the adult friendships; higher quality, supportive friendships are expected to result in better outcomes for parents and children than are conflictual, troublesome friendships.

Little work has focused on the links between the quality of parents' friendships and the quality and/or quantity of children's friendships. The exception is a recent study that compared mother's ratings of their own best friendships with the quality of their children's friendships (Doyle, Markiewicz, \& Hardy, 1994). Children of mothers whose best friends were interesting and had stimulating ideas were more likely to have a reciprocal best friend and rated that friend as more helpful and supportive. Children who experienced more closeness with their best friend had mothers who reported having supportive friends. If a mother felt less secure about her best friendship but also rated that friend as interesting, her child was more likely to have a reciprocal best friend. The Doyle et al. study provided some preliminary evidence of how the quality of parental friendships is related to children's friendship quality, but this study was limited by its ex-

(C) 2001 by the Society for Research in Child Development, Inc. All rights reserved. 0009-3920/2001/7202-0016 
amination of only maternal friendships and its reliance on self-report measures of children's friendships. The current study extends this work by examining the relations between children's friendships and the quality of paternal as well as maternal friendships. In addition, the current study provides both observational and selfreport measures of children's friendships. Each of these issues is discussed below.

Recent research suggests that fathers, as well as mothers, play important roles in children's social development, including their peer relationships (Lamb, 1997; Parke, 1996). However, the focus of prior work has been on a variety of aspects of the father-child relationship, such as the quality of attachment and the father's play style, in the development of children's friendships, with little attention devoted to the part played by the father's own patterns of friendship with other adults (Youngblade \& Belsky, 1992). Prior studies of social networks offer some insight into the potential role of fathers' friendships in the development of children's friendships. For example, Oliveri and Reiss (1987) found that the quality of fathers' friend networks, as assessed through social networks, was more closely related to the relationship aspects of adolescents' friend networks (e.g., feelings of closeness). In contrast, the structural aspects of mothers' friend networks were more closely related to the structure of adolescents' friend networks (e.g., size, density). Other studies, however, found either no link or a negative relation between fathers' social networks and children's social adjustment (Manetti \& Schneider, 1996; Roberts, 1989), which suggests that this issue needs further attention. Other findings suggest that fathers play an important role in the regulation of children's emotions - a central ingredient in the maintenance of close friendships (Gottman, Katz, \& Hooven, 1997; Parke, 1996). This prior work underscores the relevance of fathers and fathers' friendships for understanding children's friendship patterns, and suggests that the quality of both fathers' and mothers' friendships will be related to children's friendship patterns. Another goal of the present study was to describe the differential relations between maternal and paternal friendships and children's friendships.

Although it is expected that both mothers' and fathers' friendships are related to children's friendships, prior work suggests that mothers and fathers may have different patterns of relationships with sons and daughters. Both theory and empirical evidence suggests that same-gender relationships (i.e., mother-daughter, father-son) will be stronger than cross-gender relationships (i.e., mother-son, fatherdaughter). First, classical theories of identification
(Bronfenbrenner, 1960) would suggest that samegender associations are stronger. Similarly, empirical research suggests that fathers are more involved with sons, whereas mothers tend to be more involved with their daughters during middle childhood (Crouter \& Crowley, 1990) and adolescence (Harris \& Margolin, 1991). Moreover, earlier work suggests that fathers' behaviors are especially likely to be related to boys' peer relationships whereas mothers' behaviors are more closely related to girls' peer relationships (Isley, O'Neil, Clatfelter, \& Parke, 1999; MacDonald \& Parke, 1984; Youngblade \& Belsky, 1992).

\section{Measuring Friendship}

Most research on the quality of children's friendships has been based on children's social cognitions through the use of self-report (Berndt, 1981). Children's perspectives on their own friendships are useful for evaluating certain aspects of the relationship (e.g., loyalty, disclosure, and closeness), as indicated by the relations between self-reports of friendship quality and a variety of social outcomes, such as loneliness and sociometric status (Asher, Parker, \& Walker, 1996; Parker \& Asher, 1993). In fact, some aspects of friendship may only be detectable through the use of children's self-reports. For example, selfdisclosure, in which an individual shares personal, private information or feelings, is probably more easily measured by children's reports than by others' observations. There are problems, however, with relying solely on children's self-reports of friendship qualities. First, children's answers are dependent on their verbal and cognitive skills (Siegal, 1991), which may lead to a distorted report of the nature of the relationship. Second, self-reports of friendship may not reveal all aspects of the relationship (Parker \& Gottman, 1989), such as the manner in which conflict is resolved or the cognitive sophistication during play exchanges (e.g., the quality of themes or the level of play organization). Observational measures of friendship may reveal aspects of the friendship that are less accessible through self-reports.

Evidence for the assumption that self-report and observational measures of friendship may be accessing different aspects of friendships comes from earlier reports that found only modest correlations between these two types of data. In studies using both self-report and observational measures of the same construct, correlations between the two sources of assessment were not found either for children's selfdisclosure (Hobart, 1987) or for their prosocial behavior (Berndt, 1986). This low concordance suggests that these two approaches may tap different 
aspects of a friendship and underscore the need to utilize different methods to provide a more complete picture of a friendship. In the present study, both self-report and observational measures of friendship were utilized to avoid the problems of a partial assessment of the children's friendship. Because few observational measures of childhood friend-friend interaction are available, another aim of the current study was to validate a new observational measure of friendship (the Observed Friendship Quality Scale) and compare observed behavior to self-reported ratings of friendship quality. The self-report questionnaire and observational measure assess similar and distinct aspects of a friendship. Based on prior research (Berndt, 1986; Hobart, 1987), it was expected that there would be low correspondence between self-report and observational measures assessing similar constructs (e.g., reported conflict and observed negative behavior). Further, the correspondence between different friendship qualities assessed by the two measurement types (e.g., reports of validation of feelings and leading behavior) would also be low. Moreover, in light of the fact that there is greater correspondence between sources of data that rely on similar methods (e.g., self-reports) than between data derived from different methods (e.g., self-reports versus observational measures; Radke-Yarrow, 1989), it was expected that parental self-reports of friendship would be more strongly associated with children's self-reports of friendship than with observation-based indices of children's friendships.

This study was designed to test the following hypotheses: (1) the quality of parental friendships is positively related to the quality of children's friendships although there will be stronger relations between parents' and children's self-reports than between parents' self-reports and observation-based measures of children's behavior; (2) both mothers' and fathers' friendship qualities are related to their children's friendship qualities, but the relations between children's and parents' friendships differ depending on gender of the parent; and (3) there is low concordance between observation-based measures (the Observed Friendship Quality Scale) and selfreport measures (the Friendship Quality Questionnaire) of friendship quality.

\section{METHOD}

\section{Participants}

One hundred twenty-five 9-year-old children (67 boys, 58 girls) from a public school district in the western portion of the United States participated in this study. ${ }^{1}$ The children were first evaluated in kindergarten using sociometric procedures. A range of children were selected based on their sociometric data. Letters regarding the overall project were sent to the parents of these children requesting agreement to participate in the study.

Mothers' ages ranged between 28 and 50 years $(M=$ $35.86, S D=4.72)$; the mean age of fathers was 38.45 years $(S D=5.57)$ with a range of 27 to 59 years. About half of the sample was non-Latino White $(52.7 \%$ of mothers, $50 \%$ of fathers) with Latino representing the next largest group (39.5\% mothers, $40 \%$ fathers). The remainder of the sample was African American (3.9\% mothers, $4.7 \%$ fathers), and unspecified (3.9\% mothers, $4.7 \%$ fathers). Maternal and paternal education ranged from 4 to 20 years $(M=12.75, S D=2.56$ for mothers; $M=13.32, S D=2.52$ for fathers). The families' income levels ranged from $\$ 10,000$ to over $\$ 50,000$. The median income level was between $\$ 38,000$ and $\$ 42,000$.

In one of two visits to the laboratory, the target children brought a self-selected, same-gender friend. Most of the dyads (95\%) were not related. Although the other $5 \%$ were cousins, both children in each dyad labeled each other as friends. There were no mean differences between nonrelated and related friends. Thirty-six percent of the dyads were in the same classroom at school; another $26 \%$ attended the same school. Sixty percent of the dyads lived within 1 mile of each other; $22 \%$ lived 1 to 5 miles apart. All of the children nominated each other as reciprocal friends. Reciprocal friendship was measured by comparing the target child's and friend's evaluation of the level of their friendship: best friends, close friends, just a friend, or acquaintances. Nearly half of the friends were non-Latino White (46\%); 35\%, Latino; 7\%, African American; 2\%, Asian American; and 9\%, unspecified. Friends ranged between 7 and 12 years in age $(M=9.50, S D=.87)$. Most of the friends were in

\footnotetext{
${ }^{1}$ This study was part of a larger multiwave longitudinal project; participants consisted of four different cohorts. Cohort 1 consisted of participants whose families started in the project when the children were in kindergarten $(n=48)$. Subsequent cohorts were added to increase statistical power and to replace children from specific sociometric categories who did not continue in the study. Thus, a second cohort was added during the second year $(n=$ $9)$. The third cohort was added in the fourth year $(n=4)$, and the last cohort was recruited in the fifth year $(n=64)$. There were no mean differences between the cohorts on the measures collected. To complement this study's existing analyses and to further justify the inclusion of participants in the second and third cohorts, the results with and without data from these participants were examined. The pattern of findings remained similar, but to maximize the sample sizes, it was decided to retain all participants in the analyses.
} 
fourth grade $(75 \%)$ during the data collection with a range from second through seventh grade.

A pool of fourth-grade unacquainted peers was used to validate the observational measure. These individuals attended schools and resided in different cities from those of the target children. For the second visit, one unacquainted peer from the unacquaintedpeer pool was randomly selected to participate. The target child and unacquainted peer were always of the same gender and age ( 9 years old). The pool of 28 unacquainted peers included 13 boys and 15 girls. Twenty of these children were non-Latino White, six were Latino, one was Asian American, and one was African American.

\section{Procedure}

Each family completed two visits to a university laboratory. During the first visit, the target child, mother, and father participated in various videotaped tasks and completed questionnaires and interviews. The parental measure of interest for this report, the Adult Friendship Quality Questionnaire, was completed during this visit. If the parents' first language was Spanish, the Adult Friendship Quality Questionnaire was written in Spanish and a Spanish-speaking staff member administered all the questionnaires and interviews to those parents.

During the second visit, the target child, friend, and unacquainted peer participated in several videotaped tasks. First, the target child and friend participated in free play and hand games. Next, the target child and the unacquainted peer participated in free play and planned a trip. The target child and friend were brought together again to play UNO (a commercial card game), plan a trip, and complete a discussion task. Two tasks, free play and the planning activity, were used in the analyses presented in this article, because these segments evidenced the greatest variance in behaviors. In free play, each dyad was brought into a playroom and instructed that they could play with any of the toys for 5 minutes. The playroom contained a couch, a table with two chairs, and a bookshelf containing several toys, such as puppets, balls, two racquets, and stuffed animals. In the planning activity, the two children sat across from each other at a table and planned a trip to an amusement park or a camping trip together. On the table was a list of items they needed to plan. The children had to agree on several aspects of the trip, including the destination, time, duration, and activities during the trip (specifically, when to go, where to go, how long to stay, what to do first, three things to eat, three things to do/three rides to go on, and three songs to sing by the campfire/ what souvenir to bring home). The dyads were asked to agree on each decision to try to elicit more dialogue from the children. These two trips (i.e., amusement park and camping trip) were counterbalanced by the families' identification numbers. The planning activity lasted for as long as the children needed to plan the trip. The range was 5 to 25 minutes $(M=15.5, S D=2.65)$.

In addition to the observational tasks, the target children completed the Friendship Quality Questionnaire (FQQ) with a staff member. The target children's mothers also filled out a friend information form that assessed general information about the target child's friend (e.g., how far away does the friend live?), which is summarized in the sample section.

\section{Child Measures}

The FQQ. This questionnaire (Parker \& Asher, 1993) consists of 40 statements that characterize a friendship or one's friend. Each child rated how true each statement was for his or her friendship on a 5-point scale $(0=$ not at all true, $4=$ really true $)$. The target children's responses were partitioned according to six subscales identified by Parker and Asher, with the following Cronbach $\alpha$ s: disclosure, .90; help, .90; conflict, .85; conflict resolution, .85; companionship, .85; and validation, .88 .

The Observed Friendship Quality Scale (OFQS). This observational measure, developed by Flyr, Howe, and Parke (1995), was used to evaluate two segments; the free-play segment and the planning activity. The scale consists of 17 individual and 10 dyadic codes. The definitions of these codes are presented in the Appendix. These behavioral codes were based on several studies concerning children's behavior with friends (Conger \& McLeod, 1977; Dishion, Patterson, \& Griesler, 1994; Gottman, 1983; Parker, Levendosky, \& Okun, 1993; Youngblade, Park, \& Belsky, 1993). The current scale represents the range of behaviors, affect, and verbalizations examined in each of these studies. Coders watched each segment three times to rate the one dyadic and two individual scales. The first author coded the entire data set. A trained undergraduate coded $21 \%$ of the segments. Interrater reliability was computed on the segments coded by both people. ${ }^{2}$

Each child was rated on a 5 -point scale $(1=$ not at all

\footnotetext{
${ }^{2}$ Training in use of the OFQS lasted 10 weeks. The first author and the trained undergraduate student met with the author of the OFQS to go over the definition of each code and behavioral examples. After this first step, the author and trained undergraduate practiced using the scale on children's interactions with friends and nonfriends. After training, a new set of videotaped segments was used for reliability.
} 
characteristic, 5 = highly characteristic) on the following individual dimensions, with interrater reliability (Cronbach $\alpha$ s as follows): (1) involvement with, interest in, attention to, talking with, and orientation toward peer, .73; (2) directs proactive behavior toward peer, .57; (3) responds positively to initiations made by peer, .78; (4) directs negative behavior toward peer, .85; (5) responds negatively toward peer, .83 ; (6) is dominant or plays the role of leader, $.81 ;(7)$ is controlled by the peer and plays the role of follower, .80 ; (8) employs social strategies to pursue goals, .83; (9) engages in angry coercion, .15; (10) engages in guilty coercion, .56; (11) demonstrates positive affect and/or enthusiasm and/or comfortableness, .86; (12) demonstrates negative affect, .80; (13) makes statements that provide important information about his/her character, .70; (14) displays aversive physical contact, .45; (15) demonstrates cognitive sophistication, .76; (16) engages in positive fantasy play, .85; and (17) engages in negative fantasy play, .91 .

The dyadic ratings were based on the behavior of the two children together. These ten dimensions were also rated on the same 5-point scale indicating how much each item characterized the dyad's interactions. Cronbach $\alpha$ s for interrater reliability on the 10 items were: (1) awareness of each other, actions are positively linked, .76; (2) behavior is noncontingent, .74; (3) conflict, disagreement, or aversive interchanges, .86; (4) cognitive sophistication, .67; (5) physical proximity, .85; (6) competition, .91; (7) cooperation on tasks, $.71 ;(8)$ discussion of private or personal information, .89; (9) gossip, .89; and (10) attribution of feeling, motive, personality trait, or opinion, mind-reading, .79 .

\section{Parent Measures}

The Adult Friendship Quality Questionnaire was adapted from the FQQ developed by Parker and Asher (1993); some of the questions were reworded for age appropriateness. Both mothers and fathers were asked to think of a specific best friend when responding to the questionnaire, but were instructed to exclude their spouse as the best friend. As with the child version, the parents rated how true each statement was on a 5-point scale $(0=$ not at all true, $4=$ really true). Parker and Asher's six subscales were used with the mothers' and fathers' friendship questionnaires. Cronbach $\alpha$ s indicating reliability of the subscales for mothers $(\mathrm{M})$ and fathers $(\mathrm{F})$ were: disclosure, $\mathrm{M}=.86, \mathrm{~F}=.80$; help, $\mathrm{M}=.76, \mathrm{~F}=.77$; conflict, $\mathrm{M}=.66, \mathrm{~F}=.73$; conflict resolution, $\mathrm{M}=.72, \mathrm{~F}=.77$; companionship, $\mathrm{M}=.85, \mathrm{~F}=.87$; and validation, $\mathrm{M}=$ $.86, \mathrm{~F}=.76$.

\section{Data Reduction}

Factor analysis with a promax rotation was used to reduce the items of the OFQS. Two separate analyses were used to reduce the dyadic and individual items. In the analyses with the individual items, 30 items were entered: 15 target individual items and 15 friend individual items. Individual items 9 and 14 were dropped due to low reliability. Based on the scree plot of eigenvalues and the interpretability of the factors, three individual factors were used. From the factor analysis used to reduce the 10 dyadic items, 2 dyadic factors emerged. Each item with an absolute factor loading of .40 or greater was considered significant. Because all items had the same scale (1 to 5 ), unweighted composites based on the factor structure were used to represent the subscales.

The items that loaded on each factor were as follows. Dyadic cognitive sophistication represented dyadic cognitive sophistication, gossip, and sharing of information (eigenvalue $=0.95$ ). Dyadic negative behavior was made up of dyadic noncontingent behavior, conflict, and being positively linked (loading negatively; eigenvalue $=1.17$ ). Individual positive behavior represented target children's and friends' positive initiations, positive affect, negative affect (loading negatively), and responding negatively (loading negatively; eigenvalue $=3.26$ ). Target child dominance represented target children leading, target children following (loading negatively), friends leading (loading negatively), and friends following (eigenvalue $=$ 2.27). Individual cognitive sophistication represented target children and friends' negotiation and cognitive sophistication (eigenvalue $=2.06$ ) .

The Cronbach $\alpha$ s for the factors were: dyadic cognitive sophistication, .67; dyadic negative behavior, .62; individual positive behavior, .60; individual cognitive sophistication, .73; and target child dominance, .70. Thus, observational measure reliably captured children's behaviors while interacting in a dyad.

\section{RESULTS}

Is the OFQS a Valid Measure of Children's Behavior with Friends?

The target children interacted in the same task with their friends and, separately, with unacquainted peers. A series of $t$ tests was used to determine if the OFQS could differentiate children's behavior with friends from behavior with nonfriends (and thus, evidence discriminant validity; Table 1). When the target children's individual behavior with a friend was compared with their behavior with an unacquainted peer, several comparisons emerged as significant. Typically, 
the target children behaved more positively and negatively with a friend. On the dyadic level, target children and friends' dyadic behavior was compared with that of target children and unacquainted peers. Consistently, there were significant differences between the two dyads. The friends dyad exhibited increased mind-reading, gossip, competition, physical proximity, conflict, and positive interactions; and less noncontingent behavior and discussion of thoughts.

Is There a Correspondence between Children's Behavioral and Self-Report Data?

To understand the relations between the target children's self-reports and behavior, bivariate correlations were computed separately for boys and girls (Table 2). As expected, there were only sparse relations between self-report and observational friendship measures for girls. There was a more significant correspondence between boys' perceptions and be- havior. Boys' increased dyadic negative behavior and lower individual positive behavior were related to target children's reports of lower conflict resolution, disclosure, validation, helping, and increased conflict.

Is Friendship Quality for Mothers and Fathers Related to Children's Friendship Quality?

The substantive analyses of this study were conducted in two parts using bivariate correlations and multiple regressions to assess the associations between the Adult Friendship Quality Questionnaire and children's observed and self-reported friendship measures. In view of our hypothesis concerning the differential relations based on parents' and children's gender, the analyses were grouped by gender of the parents and children, yielding four sets of dyads: mothers-daughters, fathers-daughters, mothers-sons, and fathers-sons.

Table 1 Mean Target Children's Individual Behavior with Friend and Unacquainted Peer and Target-Friend Behavior Versus TargetUnacquainted Peer Behavior

\begin{tabular}{|c|c|c|c|c|}
\hline Subscale & $\begin{array}{l}\text { Target-Friend } \\
\text { Interaction }\end{array}$ & $\begin{array}{l}\text { Target-Peer } \\
\text { Interaction }\end{array}$ & $d f$ & $t$ Value \\
\hline \multicolumn{5}{|l|}{ Individual behavior } \\
\hline Involvement & $4.61(.62)$ & $4.53(.78)$ & 1,120 & 1.04 \\
\hline Positive initiations & $1.35(.92)$ & $1.24(.89)$ & 1,120 & $1.71^{+}$ \\
\hline Positive responses & $4.22(.87)$ & $3.88(1.15)$ & 1,120 & $2.74^{\star *}$ \\
\hline Negative initiations & $1.31(.73)$ & $1.04(.37)$ & 1,120 & $3.62^{* * *}$ \\
\hline Negative responses & $1.25(.59)$ & $1.07(.36)$ & 1,120 & $2.83^{* *}$ \\
\hline Leading behavior & $1.74(.85)$ & $1.27(.67)$ & 1,120 & $5.05^{\star * *}$ \\
\hline Following behavior & $1.52(.75)$ & $1.37(.68)$ & 1,120 & 1.58 \\
\hline Negotiation & $1.29(.53)$ & $1.12(.47)$ & 1,120 & $3.11^{* *}$ \\
\hline Angry coercion & $1.06(.23)$ & $1.02(.18)$ & 1,120 & 1.52 \\
\hline Guilty coercion & $1.19(.45)$ & $1.02(.13)$ & 1,120 & $4.00^{* * *}$ \\
\hline Positive affect & $3.90(.86)$ & $3.43(1.00)$ & 1,120 & $4.78^{\star * *}$ \\
\hline Negative affect & $1.09(.31)$ & $1.08(.46)$ & 1,120 & .18 \\
\hline Provides information & $1.18(.62)$ & $1.45(.88)$ & 1,120 & $-3.29^{* *}$ \\
\hline Aversive physical contact & $1.06(.26)$ & $1.02(.20)$ & 1,120 & 1.27 \\
\hline Cognitive sophistication & $3.39(1.13)$ & $3.24(1.40)$ & 1,120 & 1.61 \\
\hline Positive fantasy play & $1.51(.84)$ & $1.21(.55)$ & 1,120 & $3.23^{* *}$ \\
\hline Negative fantasy play & $1.13(.46)$ & $1.04(.24)$ & 1,120 & $1.94^{*}$ \\
\hline \multicolumn{5}{|l|}{ Dyadic behavior } \\
\hline Positively linked & $4.16(.87)$ & $3.75(1.05)$ & 1,120 & $3.68^{* * *}$ \\
\hline Noncontingent behavior & $1.32(.71)$ & $1.55(.83)$ & 1,120 & $-2.51^{*}$ \\
\hline Conflict & $1.29(.62)$ & $1.04(.37)$ & 1,120 & $3.90^{* * *}$ \\
\hline Cognitive sophistication & $2.91(1.07)$ & $2.72(1.28)$ & 1,120 & 1.34 \\
\hline Proximity & $2.58(.98)$ & $2.21(1.14)$ & 1,120 & $2.93^{* *}$ \\
\hline Competition & $1.93(1.15)$ & $1.31(.67)$ & 1,120 & $5.27^{* * *}$ \\
\hline Cooperation & $4.29(.75)$ & $4.28(.87)$ & 1,120 & .08 \\
\hline Discussion & $1.33(.65)$ & $1.76(1.01)$ & 1,120 & $-4.45^{\star * *}$ \\
\hline Gossip & $1.08(.28)$ & $1.01(.13)$ & 1,120 & $2.35^{*}$ \\
\hline Mind-reading & $1.07(.28)$ & $1.00(.02)$ & 1,120 & $2.59^{\star *}$ \\
\hline
\end{tabular}

Note: Numbers in parentheses are standard deviations.

${ }^{*} p<.05 ;{ }^{* *} p<.01 ;{ }^{* * *} p<.001 ;{ }^{+} p<.10$. 
Table 2 Correlations between Observed Behavior and Target Children's Self-Report of Friendship Quality

\begin{tabular}{|c|c|c|c|c|c|c|}
\hline \multirow[b]{2}{*}{ Observed Behavior } & \multicolumn{6}{|c|}{ Target Children's Self-Report } \\
\hline & Conflict & Companionship & $\begin{array}{l}\text { Conflict } \\
\text { Resolution }\end{array}$ & Disclosure & Validation & Help \\
\hline \multicolumn{7}{|l|}{ Girls } \\
\hline \multicolumn{7}{|l|}{ Dyadic behavior } \\
\hline Negative & .16 & -.07 & -.03 & .07 & .02 & .02 \\
\hline Cognitive sophistication & .13 & -.05 & .05 & .11 & -.05 & -.07 \\
\hline \multicolumn{7}{|l|}{ Individual behavior } \\
\hline Positive & -.20 & .04 & .03 & -.05 & -.03 & -.11 \\
\hline Leading & .08 & -.09 & -.08 & -.13 & -.06 & -.06 \\
\hline Cognitive sophistication & .13 & .08 & -.06 & -.01 & -.02 & .02 \\
\hline \multicolumn{7}{|l|}{ Boys } \\
\hline \multicolumn{7}{|l|}{ Dyadic behavior } \\
\hline Negative & $.51^{* * *}$ & -.16 & $-.31^{*}$ & $-.27^{*}$ & $-.40^{* * *}$ & $-.28^{*}$ \\
\hline Cognitive sophistication & $.22^{+}$ & -.12 & -.05 & -.12 & -.16 & -.15 \\
\hline \multicolumn{7}{|l|}{ Individual behavior } \\
\hline Positive & $-.39^{* *}$ & .19 & $.35^{* *}$ & $.26^{*}$ & $.39^{* *}$ & $.30^{*}$ \\
\hline Leading & -.02 & .01 & -.01 & .04 & -.14 & -.15 \\
\hline Cognitive sophistication & .18 & -.17 & .05 & -.01 & -.06 & .04 \\
\hline
\end{tabular}

${ }^{*} p<.05 ;{ }^{* *} p<.01 ;{ }^{* * *} p<.001 ;{ }^{+} p<.10$.

Mothers and daughters. Daughters' reports of conflict were negatively correlated with mothers' reports of helping, validation, and conflict resolution (Table 3). Mothers' ratings of conflict resolution were also positively related to target children's perceptions of conflict resolution. Higher maternal ratings of conflict correlated with increased dyadic negative behavior, less individual positive behavior, and less validation as reported by the female target children. Increased maternal ratings of disclosure were correlated with increased target children and friends' individual positive behavior, and less dyadic negative behavior.

Fathers and daughters. The pattern of the bivariate correlations for the fathers differed from the motherdaughter correlations (Table 3). Paternal friendships correlated with the girls' self-report data. There were no statistically significant correlations between fathers' friendships and children's behavior. Fathers' ratings of helping and conflict resolution were positively related to target children's reports of helping, conflict resolution, and validation. Validation in fathers' friendship was positively associated with ratings of companionship and conflict resolution by the target children. Paternal ratings of disclosure were related to target children's perceptions of companionship, conflict resolution, and validation.

Mothers and sons. Maternal friendship ratings were correlated with several outcomes (Table 3). First, higher levels of maternal disclosure were related to lower levels of children's dyadic cognitive sophistica- tion. Mothers' ratings of conflict resolution were positively correlated with dyadic negative behavior and target children's ratings of conflict. Higher levels of maternal ratings of helping were associated with lower levels of dyadic cognitive sophistication and higher levels of target children's leading behavior and reports of conflict. Higher maternal reports of companionship were correlated with increased dyadic negative behavior and decreased individual positive behavior.

Fathers and sons. In comparison to mothers and sons, fewer relations were evident for fathers and sons (Table 3). Higher ratings of fathers' conflict were related to increased dyadic negative behavior and lower individual positive behavior. Paternal ratings of helping were positively related to dyadic cognitive sophistication and target children's reports of disclosure. Target children's leading behavior was negatively correlated with paternal ratings of disclosure and validation.

Do Mothers' and Fathers' Friendships Make Unique Contributions to Children's Outcomes?

The distinct contribution of mothers and fathers was evident in the bivariate correlations. The pattern and strength of the relations between parental variables and children's outcomes differed according to the gender of the parent (see Table 3). To compare the mothers' and fathers' pattern of correlations, MULTICORR, a computer program designed to simultaneously compare several correlations within the same 


\begin{tabular}{|c|c|c|c|c|c|c|c|c|c|c|c|c|}
\hline \multicolumn{13}{|l|}{ Girls } \\
\hline \multicolumn{13}{|l|}{$\begin{array}{l}\text { Target children's } \\
\text { friendship quality }\end{array}$} \\
\hline Companion & -.00 & .13 & $.23^{+}$ & .18 & $.31^{*}$ & $.23^{+}$ & -.06 & -.09 & -.16 & -.14 & -.03 & -.04 \\
\hline Conflict & .14 & -.09 & -.01 & -.21 & -.13 & -.05 & .20 & -.16 & -.06 & $-.31^{*}$ & $-.23^{+}$ & $-.27^{*}$ \\
\hline Disclosure & .02 & .06 & -.03 & .06 & .17 & -.12 & .12 & -.12 & -.13 & -.09 & .03 & -.07 \\
\hline Help & -.13 & .19 & .18 & $.33^{*}$ & $.31^{*}$ & .17 & -.09 & .00 & -.02 & -.02 & -.06 & .09 \\
\hline Conflict resolution & -.20 & .21 & $.33^{*}$ & $.41^{* *}$ & $.29^{*}$ & $.34^{*}$ & -.19 & -.02 & .10 & .08 & $.23^{+}$ & .11 \\
\hline Validation & -.16 & .18 & $.24^{+}$ & $.32^{*}$ & $.35^{* *}$ & .21 & $-.23^{+}$ & -.08 & .04 & .03 & .08 & .11 \\
\hline \multicolumn{13}{|l|}{$\begin{array}{c}\text { Observation of children's } \\
\text { friendship quality }\end{array}$} \\
\hline \multicolumn{13}{|l|}{ Dyadic behavior } \\
\hline Negative & .13 & .17 & .13 & .14 & .12 & .03 & $.38^{* *}$ & -.20 & $-.26^{*}$ & $-.24^{+}$ & -.01 & -.01 \\
\hline Cognitive sophistication & -.02 & -.06 & -.12 & -.10 & .00 & -.07 & .19 & -.04 & .12 & -.01 & -.09 & .02 \\
\hline \multicolumn{13}{|l|}{ Individual behavior } \\
\hline Leading & .07 & .05 & .12 & .08 & -.06 & .05 & .12 & .15 & .01 & -.01 & -.09 & .09 \\
\hline Positive & -.00 & -.07 & -.07 & -.17 & -.06 & -.03 & $-.24^{+}$ & .12 & $.25^{+}$ & .09 & -.01 & -.04 \\
\hline Cognitive sophistication & -.10 & -.06 & -.14 & .05 & .02 & .03 & .00 & .01 & -.03 & -.10 & -.19 & -.14 \\
\hline \multicolumn{13}{|l|}{ Boys } \\
\hline \multicolumn{13}{|l|}{$\begin{array}{l}\text { Target children's } \\
\text { friendship quality }\end{array}$} \\
\hline Companion & .11 & -.02 & .00 & -.00 & -.01 & -.04 & -.02 & -.17 & .18 & .17 & -.13 & .18 \\
\hline Conflict & .13 & .16 & .04 & -.08 & -.11 & -.04 & .01 & .13 & .11 & $.23^{+}$ & $.27^{*}$ & -.01 \\
\hline Disclosure & -.05 & .14 & .15 & $.24^{+}$ & .11 & .03 & -.02 & -.09 & .19 & .11 & -.14 & .09 \\
\hline Help & -.03 & .13 & .12 & .10 & -.02 & .10 & .04 & -.13 & .08 & .11 & -.06 & .08 \\
\hline Conflict resolution & .01 & -.02 & .14 & .12 & -.11 & -.15 & .15 & -.00 & .08 & .06 & -.14 & .03 \\
\hline Validation & -.18 & -.04 & .12 & .09 & -.04 & .10 & .09 & -.07 & -.02 & -.05 & -.15 & .03 \\
\hline \multirow{2}{*}{\multicolumn{13}{|c|}{$\begin{array}{c}\text { Observation of children's } \\
\text { friendship quality } \\
\text { Dyadic behavior }\end{array}$}} \\
\hline & & & & & & & & & & & & \\
\hline Negative & $.24^{+}$ & -.06 & .05 & .10 & .06 & -.06 & -.09 & $.23^{+}$ & .06 & .12 & $.26^{*}$ & -.05 \\
\hline Cognitive sophistication & -.01 & .01 & .01 & $.22^{+}$ & -.07 & .01 & .04 & -.07 & $-.30^{*}$ & $-.21^{+}$ & -.02 & -.11 \\
\hline \multicolumn{13}{|l|}{ Individual behavior } \\
\hline Leading & -.02 & -.02 & $-.24^{+}$ & -.07 & .01 & $-.22^{+}$ & -.07 & .01 & .12 & $.22^{+}$ & .03 & .09 \\
\hline Positive & $-.28^{*}$ & .03 & -.13 & -.12 & -.12 & .02 & .07 & $-.22^{+}$ & .03 & .00 & -.18 & $.22^{+}$ \\
\hline Cognitive sophistication & .03 & .00 & .08 & .08 & .11 & .03 & -.05 & .08 & -.01 & .07 & .20 & .05 \\
\hline
\end{tabular}

${ }^{*} p<.05 ;{ }^{* *} p<.01 ;{ }^{+} p<.10$ 
matrix, was utilized to compare mother-child and father-child correlation matrices separately for boys and girls (Steiger, 1979, 1980a, 1980b). In this comparison, using the $\chi^{2}$ statistic, the hypothesis that the two correlation matrices are different was evaluated. Thus, a significant chi-square value signified that the overall pattern of correlations was different for mothers and fathers. Three different pairs of correlation matrices were compared separately for boys and girls, namely, target children's self-reports, friends' self-reports, and children's observed behavior. Of these six different comparisons, mothers' and fathers' correlation patterns or matrices differed only for female target children's self-report, $\chi^{2}(1, N=58)=5.41, p<.05$.

Regression analyses were used to examine the combined influence of maternal and paternal friendship qualities that accounts for variation in children's behavior and their self-reported quality of friendship. A set of backward regression analyses was performed due to the variable:sample size ratio. A second approach was used to select the variables for the regression analyses based on the significance of the bivariate correlations. Because this approach capitalized on the findings of the bivariate analyses, however, the backward regression approach was viewed as preferable. Both approaches yielded meaningful and similar patterns of results, but the amount of variance explained was higher in the case of the backward regressions.) In the first step, all maternal and paternal subscales were entered. In subsequent steps, maternal and paternal subscales were deleted if the $\beta$ weight was nonsignificant (i.e., $p>.10$ ). The regression equations reported in Table 4 are the equations in which more than one parental subscale predicted children's friendship qualities.

Daughters. Four regression equations emerged for daughters (Table 4). First, maternal validation, disclosure, conflict, and companionship, and paternal validation and companionship predicted children's dyadic negative behavior. This model accounted for $44 \%$ of the variance of children's negative dyadic behavior. Maternal validation, disclosure, and conflict, and paternal validation and companionship predicted children's individual positive behavior. Target children's reports of conflict were predicted by maternal reports of disclosure, help, and conflict resolution. Two paternal variables (validation and helping) were utilized to predict the target children's perceptions of disclosure.

Sons. Maternal companionship and conflict resolution accounted for $10 \%$ of the variance of children's dyadic negative behavior (Table 4). Children's individual cognitive sophistication was predicted by maternal and paternal conflict resolution. Maternal conflict resolution and validation predicted children's individual positive behavior. Maternal companionship, maternal

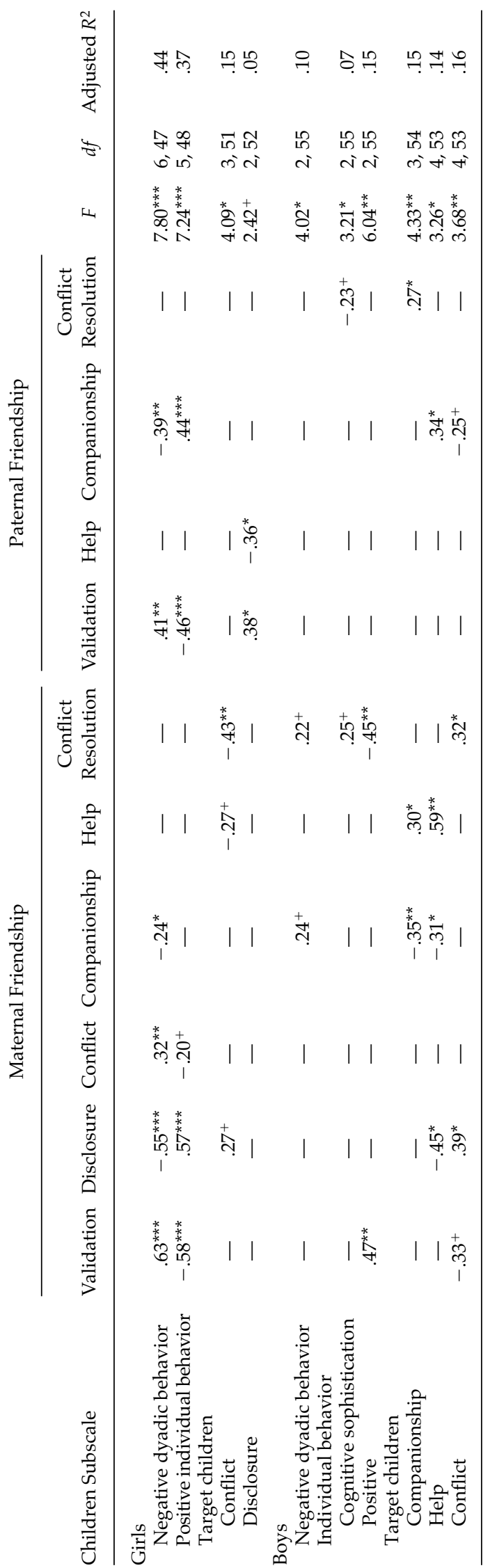

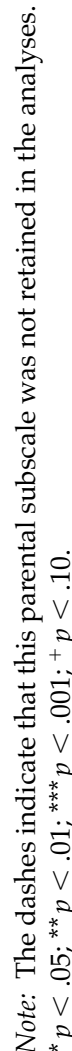


helping, and paternal helping explained $15 \%$ of the variance of the target children's reports of companionship. Target children's reports of helping were related to three maternal variables (companionship, disclosure, and helping) and paternal companionship with a model accounting for $14 \%$ of the variance. Paternal companionship and maternal conflict resolution, validation, and disclosure predicted target children's reports of conflict.

\section{DISCUSSION}

This study makes two contributions to the friendship literature: it validates a new measure to assess children's behavior with friends and suggests new links between the family and peer contexts by revealing relations between parents' and children's friendships.

\section{Measuring Friendship Quality}

The OFQS was useful for describing complex interactions between two children. First, this scale reliably measured both individual and dyadic characteristics during two different play segments. Second, it reliably differentiated between two friends' and two nonfriends' behaviors. Third, it revealed various significant associations with parents' friendship qualities. In addition, the results of this study were consistent with earlier findings based on this measure. For instance, Howe (1996) found that the scale was useful in successfully differentiating the friendship patterns of abused from those of nonabused children. Although this study focused on fourth-graders, the OFQS has also been found to be reliable with studies of children's friendships in third and fifth grade (Flyr, 1996; Simpkins, Flyr, Parke, \& Wild, 1998). This observational scale holds promise for helping to understand interactions between friends.

The expected weak relations between observed and self-reported methods of friendship assessment were largely confirmed and the pattern was consistent with that described in previous work (Berndt, 1986; Hobart, 1987). As argued earlier, the low correlations may have occurred because children's thoughts and perceptions about their friendships did not exactly correspond with the reality of their friendship interaction patterns. Further, these two assessments also measured different qualities. The behavioral measure captured leading behavior and cognitive sophistication that were not directly assessed by the self-report questionnaire. In addition, the self-report questionnaire examined children's disclosure and companionship, which are difficult to capture through observation of children. These approaches may assess overlapping perspectives of similar constructs, but they also tap nonoverlapping friendship qualities. This finding was qualified by the gender of the child, however. Specifically, male target children had numerous associations between their perceptions of a friendship and the dyad's positive and negative behavior, but with female target children, no statistically significant relation occurred. Why would male target children's perceptions be correlated with observed behavior more than female perceptions? Perhaps boys change their behavior or responses less frequently than do girls. Boys may not be as worried about how their answers on the questionnaire make them appear; thus, they may give a more accurate picture of their friendship. Our findings suggest that it is useful to include both methodologies in future studies to obtain a complete picture of children's friendships.

Finally, in addition to the possibility that different aspects of friendship are being assessed, more attention to two other factors may increase the relations between observational and self-report measures. By expanding the time frame of the observations, a more detailed picture of children's friendships may emerge; in turn, this would more likely capture a broader range of experiences and therefore more closely approximate the wealth of relationship history upon which children draw in assessing their friendships. Similarly, the use of more ecologically valid settings may yield a more representative picture of children's friendship behavior than can be observed under the constraints of the laboratory context (Hartup, French, Laursen, Johnston, \& Ogawa, 1993). More naturalistic observational studies of friendship over more extended time periods would help address this issue.

\section{Parents' and Children's Friendship Quality}

Qualities of mothers' and fathers' friendships were found to be related to their children's perceptions of their own friendships and to observed behavior of the child with a friend. Although the specific pattern of findings varied as a function of parent and child gender, there was little support for the expected differential relation between same-gender and opposite-gender parent-child pairings. Instead, both mothers' and fathers' friendship patterns were linked in interesting ways to both their sons' and daughters' friendships. These findings suggest that both gender of child and gender of parent need to be considered in future efforts to unravel the complexities of the relations between parents' and children's friendships. In the case of girls, different qualities of paternal and maternal friendships were related to daughters' friendship qualities. The positive aspects of girls' friendships (e.g., help, resolution of conflict, validation) were largely related 
to their fathers' positive friendship qualities, whereas the negative aspects of girls' friendships (e.g., observed and self-reported conflict) were related to maternal friendship qualities. Several explanations for this pattern of findings can be suggested. First, several lines of evidence suggest that fathers have a stronger impact on children's social-emotional development than do mothers. For example, Gottman et al. (1997) found that fathers' acceptance of children's emotional displays was more predictive of their children's relationships with a friend than was mothers' management of children's emotions. Similarly, the findings are consistent with previous literature, which suggests that fathers are significant contributors to children's emotional understanding, emotional regulation, and capacity to maintain playful exchanges (Parke, 1996); in turn, these abilities are important correlates of children's friendship competence. Second, a selective explanation of exposure suggests that fathers are more likely to shield girls from exposure to friendship-related conflict, whereas mothers may be more likely to expose girls to friendship-related conflict as a way of indirectly teaching them to better manage conflict in close relationships.

Boys' friendship patterns were only sparsely related to both mothers' and fathers' self-reports of friendship quality. Girls' friendships had more overall relations to parents' friendships than did those of boys. Perhaps girls have more contact than boys with their parents' best friends because boys spend more time away from home than do girls (Hoffman, 1977). This result could also be due to the size differences in children's friendship and playmate networks, where girls only have a few close friends and boys are part of larger groups (Maccoby, 1990). Therefore, parents' best friendships may be more significant for girls because girls' friendships are intimate and small in number. On the other hand, boys have a larger number of friends and the qualities of parental friendships may be less relevant for the more diffuse, grouporiented nature of boys' friendships. Perhaps parents' social networks may be more significant for boys' friendship patterns. Future research is needed to determine the mechanisms that account for these differing relations for boys and girls.

Although some of the findings of this study were consistent with expectations, such as the reported level of friendship-related paternal conflict being negatively correlated with boys' positive friendship quality (observed), other findings were unexpected. Several positive parental variables were unexpectedly positively correlated with negative child outcomes or vice versa. This pattern of results concerning the links between parents and children's social relationships has been found by other researchers (Doyle \& Mar- kiewicz, 1996; Doyle et al., 1994; Simpkins, O'Neil, Lee, Parke, \& Wang, 1999; Youngblade \& Belsky, 1992). In the current study, for example, maternal conflict resolution positively predicted boys' negative behavior. Results such as these may not be counterintuitive, because friendships encompass both positive and negative qualities (Hartup et al., 1993; Howes, 1983; Newcomb \& Bagwell, 1995). Perhaps through their parents, children understand how to behave within the context of a friendship that includes qualities such as dominance and conflict as well as positive features such as helping, sharing, and conflict resolution.

\section{Limitations and Future Directions}

Although this study has uncovered links between parents' and children's friendship patterns, it has several limitations. Even though parents' and children's friendship patterns are related, the results are correlational in nature and no inferences concerning direction of causality can be made. The current research did not examine the mechanisms that would explain the links between parents' and children's friendships. Several mechanisms should be the focus of investigation in future research; they include observational learning (Bandura, 1989), direct parental instruction or coaching concerning appropriate ways of relating to friends (Parke \& Ladd, 1992), and cognitive working models of social relationships, which derive from earlier infantparent attachment relationships and guide child friendship patterns (Sroufe, Carlson, \& Shulman, 1993). Moreover, both direct and indirect pathways between parents' and children's friendships need to be explored. Evidence from earlier studies supports an indirect influence, in which the parents' friendships enhance their own well-being or parenting style, which in turn affects the child's social adjustment (Daniels \& Moos, 1988; Simons, Lorenz, Wu, \& Conger, 1993). A direct route, consisting of the parent teaching or modeling appropriate social skills or behavior, is also possible (Bhavnagri \& Parke, 1991; Finnie \& Russell, 1988). Examination of these pathways is an important direction for future research. Finally, the generalizability of these findings is limited in terms of both age and ethnicity of children. Although European American and Mexican American children participated in the study, the sample sizes did not permit a comparison of the relative strength of the relations across the two ethnic groups. Direct exploration of these issues would be worthwhile.

\section{ACKNOWLEDGMENTS}

This research was supported by NSF Grant BNS 8919391 to Ross D. Parke and NICHD Grant HT 32391 
to Ross D. Parke and Robin O'Neil. The authors would like to thank the Fontana and Jurupa Unified School Districts for their generous and continued support of the University of California at Riverside Social Development Project, and are especially grateful to all of the families whose ongoing involvement made this project possible.

\section{ADDRESSES AND AFFILIATIONS}

Corresponding author: Sandra D. Simpkins, Institute for Social Research, University of Michigan, Ann Arbor, MI 48106; e-mail: sandisim@isr.umich.edu. At the time of this study, she was with Ross D. Parke at the University of California, Riverside.

\section{APPENDIX \\ DEFINITIONS OF INDIVIDUAL AND DYADIC CODES FOR THE OBSERVED FRIENDSHIP QUALITY SCALE}

\section{Individual codes}

Involvement: The intensity and duration of being aware of the peer, engaging in conversation or play, knowing where the other child is, watching the other child, initiation of interaction, and participation with the other child.

Positive initiations: The intensity, frequency, and duration of proactive behavior, including spontaneous sharing; giving a compliment, and solicitations; or empathic behavior such as helping, courteous requests, initiation or maintenance of play, and invitations. All of these must be initiations, not responses.

Positive responses: The frequency, duration, and intensity of compliance, sharing, soliciting, complimenting, laughing in response, and joining in play.

Negative initiations: The frequency, duration, and intensity of intrusive behavior; stealing or snatching toys; physical or verbal aggression; angry behavior; unfriendly, demeaning statements or tone of voice.

Negative responses: The frequency, duration, and intensity of refusal of objects or play; angry or aggressive responses; rebuffing of a positive initiation; grabbing an object that is not offered; actively ignoring a bid; or actions with negative affect.

Leading: The extent to which a child exerts disproportionate control over what happens, such as being bossy or controlling, and defining the activities or rules.

Following: The extent to which a child lets another control his or her behavior or is submissive, such as evoking directions from the other, complying with their directives, or going along with anything the peer does.

Negotiation: Child's use of strategies to attain goals, including trading, number of strategies, bargaining, rationalization of strategies, persuading, or talking about the problem. The child does not have to be successful with these strategies.
Angry coercion: The intensity and frequency of threatening and derogatory directives that demand specific behavior change. This includes such things as verbal and nonverbal threats that imply physical, psychological, or emotional harm.

Guilty coercion: The intensity and frequency of the use of guilt in manipulating the behavior of the peer (e.g., if a child says "That really hurts my feelings when you say that").

Positive affect: The frequency and intensity of such behavior and affect as ease of movement, relaxed body posture, enthusiasm, smiling, level of enjoyment, vocalizations, and positive facial expressions.

Negative affect: The frequency and intensity of verbally or behaviorally negative feelings, such as postural expressions, pouting, stomping feet, throwing toys, unpleasant vocal tones, and angry facial expressions.

Provides information: Information about the self, including feelings, traits, likes/dislikes, relationship issues, selfevaluation, family experiences, skills or skill deficits, or recurring behaviors.

Aversive physical contact: The frequency and intensity of behaviors such as hitting, kicking, pushing, grabbing, hair pulling, but not including the destruction of objects unless they are used to hurt the peer.

Cognitive sophistication: The extent to which a child's behavior shows meaningful and coherent responses, including duration and content of conversations; the extent to which an activity is organized and planned according to rules.

Positive fantasy play: The frequency and intensity of imaginative characters, places, and scenes acted out. All roles, themes, and occurrences are of a happy, peaceful, and generally positive nature.

Negative fantasy play: The frequency and intensity of imaginative characters, places, and scenes acted out. All roles, themes, and occurrences are of a destructive nature, where harm is intended for other individuals and objects.

\section{Dyadic codes}

Positively linked: The extent to which two children are relating to one another. This includes mutual pleasure (e.g., laughing); smiling; getting along well; cooperative, considerate, nice behavior toward each other; and joint positive pretend play.

Noncontingent behavior: The disharmony of the children's interaction. Overt indicators include not partaking of the other's agenda, talking at the same time, interrupting each other, invading the other's space, intrusiveness, unresponsiveness, and imbalance, where one child dominates, or the children's goals do not match.

Conflict: Conflict, disagreement, or aversive interchanges.

Cognitive sophistication: The duration and intensity of children's sophistication in play, including play organization, development of themes, and imaginative/pretend play.

Proximity: How much of the time children spend within 5 feet of each other. 
Competition: The extent to which the children try to show that one is better than the other. This includes comparisons of self or performance and attention-seeking behaviors.

Cooperation: The extent to which the partners listen to each other regarding instructions, cooperate on tasks, and avoid becoming sidetracked.

Discussion: The extent of a reciprocal exchange of personal information.

Gossip: The frequency, intensity, and duration of the children's exchange of statements about another person that both children know.

Mind-reading: This code defines the extent to which the children engage in making statements that give the appearance that each is reading the mind of the other (e.g., "You don't like Roy," when the peer makes a face). The children appear to understand each other's feelings, opinions, and behaviors without talking about it.

\section{REFERENCES}

Asher, S. R., Parker, J. G., \& Walker, D. L. (1996). Distinguishing friendship from acceptance: Implications for intervention and assessment. In W. M. Bukowski, A. F. Newcomb, \& W. W. Hartup (Eds.), The company they keep: Friendship in childhood and adolescence (pp. 366-407). New York: Cambridge University Press.

Bagwell, C. L., Newcomb, A. F., \& Bukowski, W. M. (1998). Preadolescent friendship and peer rejection as predictors of adult adjustment. Child Development, 69, 140-153.

Bandura, A. (1989). Social cognitive theory. In R. Vasta (Ed.), Annals of child development: Vol. 6. Six theories of child development: Revised formulations and current issues (pp. 160). Greenwich, CT: JAI Press LTD.

Berndt, T. J. (1981). Relations between social cognition, nonsocial cognition, and social behavior: The case of friendship. In J. H. Flavell \& L. D. Ross (Eds.), Social cognitive development: Frontiers and possible futures (pp. 176-200). Cambridge, U.K.: Cambridge University Press.

Berndt, T. J. (1986). Sharing between friends: Contexts and consequences. In E. C. Mueller \& C. R. Cooper (Eds.), Process and outcome in peer relationships (pp. 105-127). New York: Academic Press.

Bhavnagri, N., \& Parke, R. D. (1991). Parents as direct facilitators of children's peer relationships: Effects of age of child and sex of parent. Journal of Social and Personal Relationships, 8, 423-440.

Bronfenbrenner, U. (1960). Freudian theories of identification and their deviations. Child Development, 31, 15-40.

Cochran, M. M., \& Brassard, J. A. (1979). Child development and personal social networks. Child Development, 50, 601-616.

Conger, R., \& McLeod, D. (1977). Describing behavior in small groups. Behavioral Methods and Instrumentation, 9, 418-424.

Crouter, A. C., \& Crowley, M. S. (1990). School-age children's time alone with fathers and single and dualearner families: Implications for the father-child relationship. Journal of Early Adolescence, 10, 296-312.
Daniels, D., \& Moos, R. H. (1988). Exosystem influences on family and child functioning. Journal of Social Behavior and Personality, 3, 113-133.

Dishion, T. J., Patterson, G., \& Griesler, P. (1994). Peer adaptations in the development of antisocial behavior: A confluence model. In L. R. Huesmann (Ed.), Aggressive behavior: Current perspectives (pp. 61-95). New York: Plenum Press.

Doyle, A. B., \& Markiewicz, D. (1996). Parents' interpersonal relationships and children's friendships. In W. M. Bukowski, A. F. Newcomb, \& W. W. Hartup (Eds.), The company they keep: Friendship in childhood and adolescence (pp. 115-137). New York: Cambridge University Press.

Doyle, A. B., Markiewicz, D., \& Hardy, C. (1994). Mothers' and children's friendships: Intergenerational associations. Journal of Social and Personal Relationships, 11, 363377.

Finnie, V., \& Russell, A. (1988). Preschool children's social status and mothers as supervisors. Developmental Psychology, 24, 789-801.

Flyr, M. L. (1996). The influence of parental advice giving on children's friendship. Unpublished doctoral dissertation, University of California, Riverside.

Flyr, M. L., Howe, T. R., \& Parke, R. D. (1995). Observed friendship quality scale [Unpublished coding system]. University of California, Riverside.

Gottman, J. M. (1983). How children become friends. Monographs of the Society for Research in Child Development, 48 (3, Serial No. 201).

Gottman, J. M., Katz, L. F., \& Hooven, C. (1997). Meta-emotion: How families communicate emotionally. Mahwah, NJ: Erlbaum.

Harris, K. M., \& Margolin, S. P. (1991). Fathers, sons and daughters: Differential paternal involvement in parenting. Journal of Marriage and the Family, 53, 531-544.

Hartup, W. W., French, D. C., Laursen, B., Johnston, M. K., \& Ogawa, J. R. (1993). Conflict and friendship relations in middle childhood: Behavior in a closed-field situation. Child Development, 64, 445-454.

Hartup, W. W., \& Stevens, N. (1997). Friendships and adaptation in the life course. Psychological Bulletin, 121, 355370.

Hobart, C. J. (1987, April). Behavioral interactions of friends and acquaintances in childhood and adolescence. Paper presented at the biennial meeting of the Society for Research in Child Development, Baltimore, MD.

Hoffman, L. W. (1977). Changes in family roles: Socialization and sex differences. American Psychologist, 32, 644657.

Homel, R., Burns, A., \& Goodnow, J. (1987). Parental social networks and child development. Journal of Social and Personal Relationships, 4, 159-177.

Howe, T. (1996). Friendship quality, sociometric status, and loneliness in abused and non-abused children. Unpublished doctoral dissertation, University of California, Riverside.

Howes, C. (1983). Patterns of friendship. Child Development, 54, 1041-1053.

Isley, S. L., O'Neil, R., Clatfelter, D., \& Parke, R. D. (1999). Parent and child expressed affect and children's social 
competence: Modeling direct and indirect pathways. Developmental Psychology, 35, 547-560.

Ladd, G. W., \& Le Sieur, K. D. (1995). Parents and children's peer relationships. In M. H. Bornstein (Ed.), Handbook of parenting (pp. 337-409). Mahwah, NJ: Erlbaum.

Lamb, M. E. (1997). The role of the father in child development (3rd ed.). New York: Wiley.

Maccoby, E. E. (1990). Gender and relationships. American Psychologist, 45, 513-520.

MacDonald, K., \& Parke, R. D. (1984). Bridging the gap: Parent-child play interaction and peer interactive competence. Child Development, 55, 1265-1277.

Manetti, M., \& Schneider, B. H. (1996). Stability and change in patterns of parental social support and their relation to children's school adjustment. Journal of Applied Developmental Psychology, 17, 101-115.

Newcomb, A. F., \& Bagwell, C. L. (1995). Children's friendship relations: A meta-analytic review. Psychological Bulletin, 117, 306-347.

Oliveri, M. E., \& Reiss, D. (1987). Social networks of family members: Distinctive roles of mothers and fathers. Sex Roles, 17, 719-738.

Parke, R. D. (1996). Fatherhood. Cambridge, MA: Harvard University Press.

Parke, R. D., \& Ladd, G. W. (1992), Family-peer relationships: Modes of linkage. Hillsdale, NJ: Erlbaum.

Parker, J. G., \& Asher, S. R. (1993). Friendship and friendship quality in middle childhood: Links with peer group acceptance and feelings of loneliness and social dissatisfaction. Developmental Psychology, 29, 611-621.

Parker, J. G., \& Gottman, J. M. (1989). Social and emotional development in a relational context: Friendship interaction from early childhood to adolescence. In T. J. Berndt \& G. W. Ladd (Eds.), Peer relationships in child development (pp. 95-131). New York: Wiley.

Parker, J. G., Levendosky, A., \& Okun, A. (1993, April). Cooperative and competitive behavior among abused children and their close friends. Poster presented at the biennial meeting of the Society for Research in Child Development, New Orleans, LA.

Radke-Yarrow, M. (1989). Developmental and contextual analysis of continuity. Human Development, 32, 204-209.
Roberts, W. L. (1989). Parents' stressful life events and social networks: Relations with parenting and children's competence. Canadian Journal of Behavioral Science, 21, 132146.

Siegal, M. (1991). Knowing children: Experiments in conversation and cognition. Hove, U.K.: Erlbaum.

Simons, R. L., Lorenz, F. O., Wu, C. I., \& Conger, R. D. (1993). Social network and marital support as mediators and moderators of the impact of stress and depression on parental behavior. Developmental Psychology, 29, 368-381.

Simpkins, S. D., Flyr, M. L., Parke, R. D., \& Wild, M. N. (1998, August). Observation, perception, and stability of children's friendship. Paper presented at the annual meeting of the American Psychological Association, San Francisco, CA.

Simpkins, S. D., O’Neil, R., Lee, J., Parke, R. D., \& Wang, S. (1999). Parents' and children's social networks: Mediational links and relations with social competence. Unpublished manuscript, University of California, Riverside.

Sroufe, L. A., Carlson, E., \& Shulman, S. (1993). Individuals in relationships: Development from infancy through adolescence. In D. Funder, R. Parke, C. Tomlinson-Keasey, \& K. Widaman (Eds.), Studying lives through time: Personality and development (pp. 315-342). Washington, DC: American Psychological Association.

Steiger, J. H. (1979). MULTICORR: A computer program for fast, accurate, small-sample testing of correlational pattern hypotheses. Educational \& Psychological Measurement, 39, 677-680.

Steiger, J. H. (1980a). Tests for comparing elements of a correlation matrix. Psychological Bulletin, 87, 245-251.

Steiger, J. H. (1980b). Testing pattern hypotheses on correlation matrices: Alternative statistics and some empirical results. Multivariate Behavioral Research, 15, 335-352.

Youngblade, L. M., \& Belsky, J. (1992). Parent-child antecedents of 5-year-olds' close friendships: A longitudinal analysis. Developmental Psychology, 28, 700-713.

Youngblade, L. M., Park, K. A., \& Belsky, J. (1993). Measurement of young children's close friendship: A comparison of two independent assessment systems and their associations with attachment security. International Journal of Behavioral Development, 16, 563-587. 